\title{
Genetically Engineered Bacteria Immobilized in Alginate as an Option of Cyanotoxins Removal
}

\author{
Dariusz Dziga, Magdalena Sworzen, Benedykt Wladyka, and Marcin Wasylewski
}

\begin{abstract}
Microcystins (MCs), cyclic heptapeptides produced by cyanobacteria constitute a significant risk to humans. Several bacteria with MCs degradation capability are known, however their practical usage is questionable due to low MC elimination efficiency. As an alternative bacteria with significantly enhanced activity toward these hepatotoxins may be constructed. We have recently presented successful expression of the MIrA enzyme involved in MC biodegradation in E. coli BL21 strain. In this paper preliminary experiments indicating the usefulness of such modified bacteria have been showed. The MC degradation efficiency was monitored by the HPLC detection of linear MC-LR. Immobilization procedure involved the formation of alginate beads with entrapped bacterial cells. The long-term activity of BL21_MlrA in comparison with wild Sphingomonas strain confirmed much higher potential of the modified bacteria. Immobilization in alginate allowed to form beads with high activity toward MC. A column packed with alginate entrapped cells eliminated MC efficiently from contaminated freshwater. These promising results will broaden the perspective of practical application of microorganisms in bioremediation of freshwater.
\end{abstract}

Index Terms-Alginate, biodegradation, immobilization, microcystin.

\section{INTRODUCTION}

Eutrophication of surface water results in frequent occurrences of toxic cyanobacterial blooms. Certain species of cyanobacteria are capable of producing several different toxins like hepatotoxins, neurotoxins, dermatotoxins and cytotoxins with a broad range of targets; among them hepatotoxic microcystins (MCs) are the predominant cyanotoxins (Fig. 1). These cyclic peptides are stable and resistant to chemical hydrolysis or oxidation, even at high temperature [1] or low $\mathrm{pH}$ [2]. Toxicological aspects of these toxins, including promotion of liver cancer at low doses, are well known (reviews of Ibelins and Chorus [3] and Funari et al. [4]). The molecular basis of microcystin toxicity [5] is the inhibition of protein phosphatase type 1 and 2A (PP1 and PP2A) both in animals and in higher plants. This inhibition induces hyperphosphorylation of the cytosolic and cytoskeletal proteins as well as reorganization of intermediate and actin filaments [6]. Liver damage caused by

Manuscript received January 10, 2013; revised April 1, 2013. This work was supported by MNiSW, Poland (grant No 4360/B/P01/2010/39). D. Dziga and M. Sworzen are with the Department of Plant Physiology and Development, Jagiellonian University, Kraków, Poland (e-mail: daiusz.dziga@uj.edu.pl and swmaga@wp.pl, respectively).

B. Wladyka is with Department of Analytical Biochemistry, Jagiellonian University, Krakow, Poland and Malopolska Centre of Biotechnology, Kraków, Poland (e-mail: wladykab@interia.pl)

M. Wasylewski is with Faculty of Biochemistry, Biophysics and Biotechnology, Jagiellonian University, Kraków, Poland (e-mail: marcin.wasylewski@uj.edu.pl)
MCs leads to hepatic blood pooling and hypovolemic shock and eventually produces lethal effect in mammals [7], [8]. As MCs constitute a significant risk to people, the World Health Organisation has supplied a provisional guideline value of 1 $\mu \mathrm{g} \mathrm{L}^{-1}$ as the highest acceptable level of microcystin equivalents in drinking water [9].

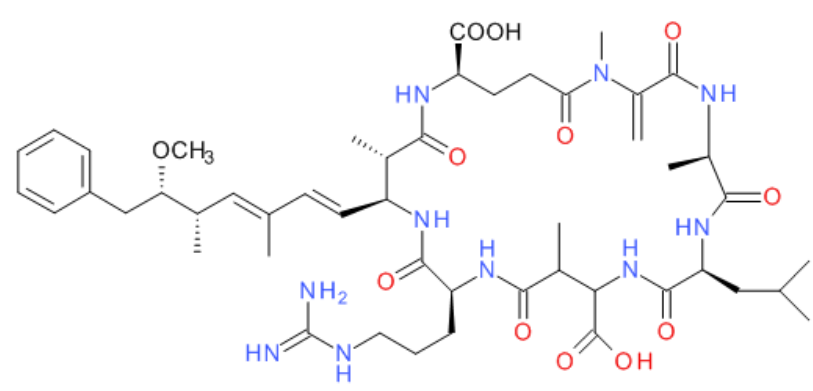

Fig. 1. The chemical structure of MC-LR, most common hepatotoxin produced by different cyanobacteria.

The persistence of soluble cyanotoxins in water reservoirs during and after bloom has important implications for both recreational and drinking water supplies. The length of time needed for their transformation into nontoxic products affects the level of accumulation in aquatic organisms. This creates a potential risk of toxin transference to humans through the food chain and of adverse health effects due to exposure to this toxin. The ambient concentration of MCs is a function of several different factors such as adsorption to particles (suspended solids and sediments), thermal decomposition aided by $\mathrm{pH}$, accumulation in aquatic plants and animals, photolysis and biodegradation by natural aquatic organisms [10], [11]. However, the details of these processes as well as the degree to which each of them contributes to MCs concentration reduction remain unknown.

The bacterial degradation pathway of MCs is known relatively well [12]; several new strains were shown to be capable of hydrolyzing different hepatotoxins in the manner primary described by Bourne et al. [13]. The crucial step in MC detoxification by bacteria is the linearization reaction catalyzed by metalloproteinase called microcystinase (MlrA). Such a decyclization results in a significant reduction of toxicity [14]. The pathway of MC degradation was confirmed independently, with small alteration due to the different strains. However, almost always the first step of MC degradation is its linearization by the MlrA enzyme. Several new bacterial species with broad affiliation were documented to express MlrA homologues.

Last year some papers documenting the heterologous expression of Mlr protein were published. Such an approach provides several advantages, due to a much higher 
production of enzymes in comparison with wild strains (Fig. 2). For example, better biochemical characterization of these important enzymes as well as the correction of their role in MCs degradation was possible [14] - [16]. Another option is to investigate the usefulness of such recombinant strains or recombinantly expressed MlrA enzyme in biotechnological application. As the estimated toxicity of linear MCs is drastically lower than of intact MCs, the use of bacteria with the expression of only MlrA enzyme with access to MCs is completely sufficient to abolish cyanobacterial heptapeptide toxicity. It simplifies significantly the development of an efficient biotechnological method for MC removal.

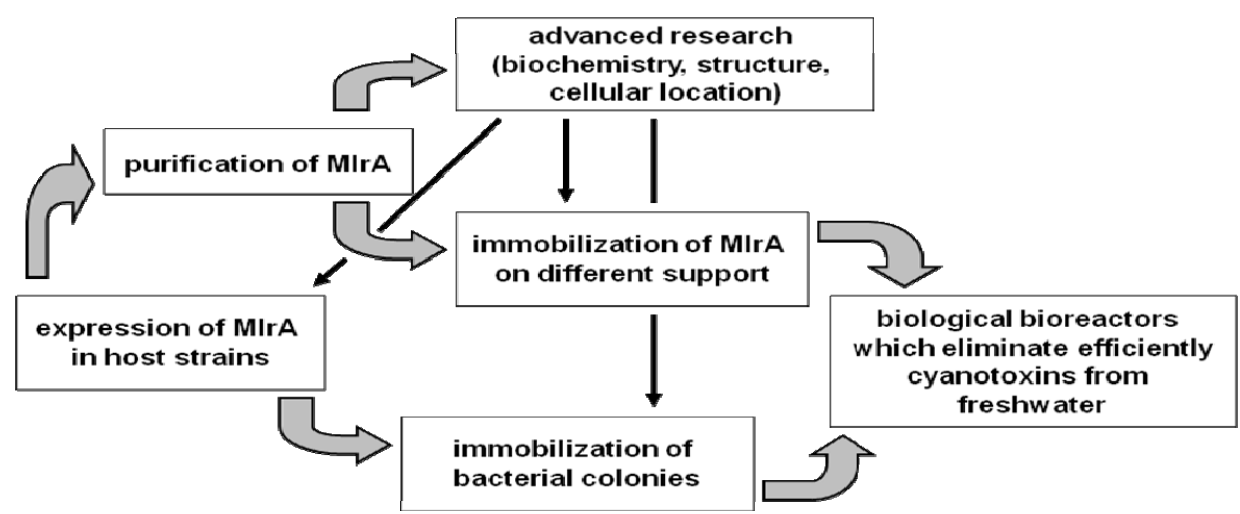

Fig. 2. Possible direction of research based on the heterologous expression of MlrA. Thick arrows indicate subsequent steps of investigation whereas thin arrows indicate possible impact of results on the other areas of study.

In the present paper preliminary experiments indicating the usefulness of a bacterial strain with overexpression of MlrA have been presented. The MC degradation capability of such modified bacteria immobilized by alginate has been tested. Additionally, the efficiency of the proposed system of $\mathrm{MC}$ removal from freshwater has been analysed.

\section{MATERIALS AND METHODS}

\section{A. Bacterial Strains}

Sphingomonas sp. ACM-3962, obtained from the Australian Collection of Microorganisms, was cultured in a recommended peptone yeast extract medium (299) at $28^{\circ} \mathrm{C}$ for 48 hours. After two days of incubation the cells were centrifuged and washed in PBS buffer. E. coli BL21(DE3) used for expression of recombinant proteins were grown at $37^{\circ} \mathrm{C}$ in $\mathrm{LB}$ broth supplemented with ampicilin $(100 \mu \mathrm{g}$ $\left.\mathrm{mL}^{-1}\right)$.

\section{B. Construction of Recombinant Plasmids and Expression of Recombinant MlrA}

The sequence from Sphingomonas sp. coding for MlrA was amplified by PCR using primer pairs described earlier [14]. The amplified fragments were inserted into the pTZ57R/T cloning vector and the sequence was verified. Subsequently, the fragments were inserted into the expression vector pET21a. The resulting plasmid pET21a-mlrA was transformed into $E$. coli BL21(DE3) and bacteria were plated on LB agar plates supplemented with ampicilin $\left(100 \mu \mathrm{g} \mathrm{mL}^{-1}\right)$.

MlrA activity of the intact Sphingomonas sp. ACM-3962 and E. coli BL21_MlrA cells was measured as described earlier using the HPLC method [14]. The rate of MCs degradation was calculated by monitoring the level of linear MC-LR.

To test the long-term MlrA activity of transformed E. coli, the cells were incubated in LB medium (100 times diluted) for 4 weeks at $20^{\circ} \mathrm{C}$. On days $1,2,5,14$ and $2110 \mathrm{~mL}$ of the sample was taken. After centrifugation the cells were resuspended in $1 \mathrm{~mL}$ of PBS and the activity toward MC-LR was analysed.

C. Immobilization of E. coli BL2_MlrA and Sphingomonas sp. ACM 3962 on Alginate

To compare the potency of transformed cells to hydrolyse MC, a degradation assays were performed for immobilized $E$. coli BL21_MlrA cells and Sphingomonas sp. ACM 3962 as natural, non-modified cells. $40 \mathrm{~mL}$ of freshly cultured bacteria ( $18 \mathrm{~h}$ - and 48h-old-culture, respectively, $\mathrm{OD}_{600} \approx 3.0$ ) were centrifuged and resuspended in $2 \mathrm{~mL}$ of $50 \mathrm{mM}$ phosphate buffer, $\mathrm{pH}=7.0$. The cell suspension was mixed with $60 \mathrm{mg}$ of slowly added sodium alginate. It was next dropped into $5 \% \mathrm{CaCl}_{2}$ to obtain beads of approximately 1 $\mathrm{mm}$ in diameter which were then incubated in $\mathrm{CaCl}_{2}$ for half an hour at $5^{\circ} \mathrm{C}$. If more immobilized bacteria needed the procedure was scale-up proportionally. To compare the ability of the immobilized cells to hydrolyse MC with the activity of intact cells, $10 \mathrm{~mL}$ of bacterial culture were centrifuged, resuspended in $0.5 \mathrm{~mL}$ of phosphate buffer and incubated with MC-LR. After $1 \mathrm{~h}$ the cells were centrifuged and the reaction was stopped by the addition of trifluoroacetic acid. Such a control assay allowed to calculate the efficiency of immobilization.

\section{Degradation of MC-LR in the Column Packed with Alginate Entrapped Cells}

A simple system of water treatment was designed to perform the removal assay of environmentally relevant concentration of MC (Fig. 3). The main part of such bioreactor was a $10 \mathrm{~mm}$ diameter glass column filled with the beads which formed a $20 \mathrm{~mm}$ high layer. In the column packed in this way the void volume was $0.6 \mathrm{~mL}$. The constant flow of MC-LR solution $\left(0.5 \mathrm{~mL} \mathrm{~min}^{-1}\right)$ resulted in $1.2 \mathrm{~min}$ of direct contact between the toxin and the alginate beads. 


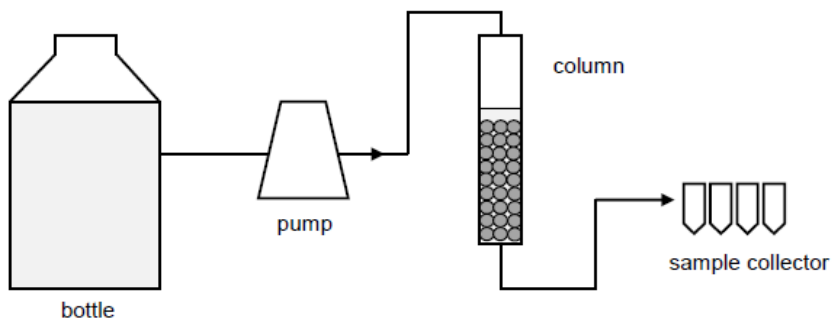

Fig. 3. Filtration system with E. coli_BL21_MlrA immobilized in alginate beads. The length of column $-20 \mathrm{~mm}$, the diameter $10 \mathrm{~mm}$, the free volume $0.6 \mathrm{~mL}$, flow rate $0.5 \mathrm{~mL} \mathrm{~min}^{-1}$

\section{RESULTS}

It was indicated previously that whole cells of $E$. coli BL21_MlrA exhibited approximately 250 times higher MlrA activity than Sphingomonas cells [14]. Furthermore, the use of IPTG to induct the MlrA expression in BL21_MlrA was not necessary, because the cells with and without induction exhibited a similar level of activity toward MC-LR (data not presented). For this reason the cultivation of BL21_MlrA in the future experiments described below was performed without IPTG induction. During long incubation of bacteria the activity was the highest on 1st day and then decreased drastically over 4 days. However, after 3 and 4 weeks $16 \%$ of the initial activity was still noticable (Fig. 4A).
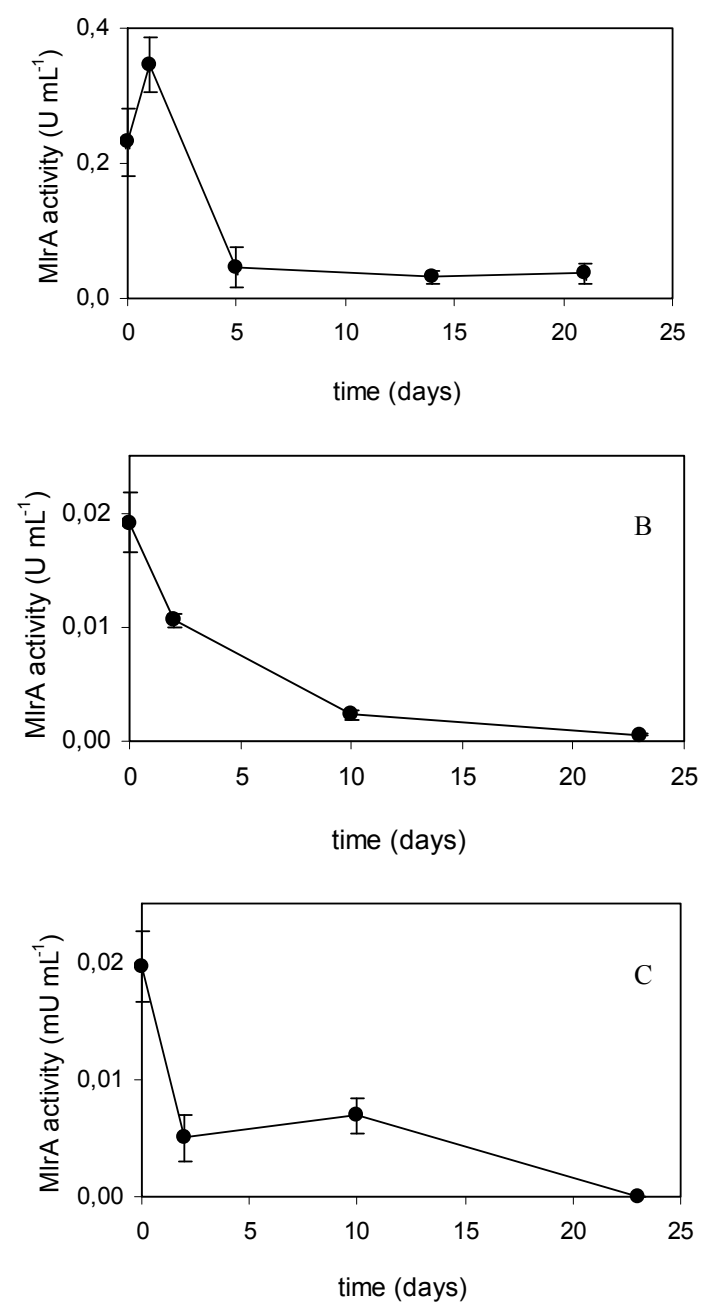

Fig. 4. Activity of free (A) and immobilized (B) cells of E. coli BL21_MlrA and immobilized Sphingomonas AMC -3962 (C) during long-term incubation in $100 \mathrm{x}$ diluted medium
The formation of alginate beads with immobilized BL21_MlrA bacteria resulted in a significant loss of MlrA activity in comparison with the cell solution (approximately $90 \%$ ). Nevertheless, the beads were still capable of MC-LR degradation and such potency was high during 3 weeks of incubation (Fig. 4B), the capability of MC degradation on day 23 was 28.6 times higher than the initial activity of the immobilized Sphingomonas sp. cells (Fig. 4C).

A simple bioreactor constructed as shown on Fig. 3 allowed to perform a preliminary experiment indicating the potency of immobilized BL21_MlrA bacteria for continuous removal of $\mathrm{MC}$ from solution. At constant flow $\left(0.5 \mathrm{~mL} \mathrm{~min}^{-1}\right)$ of the freshwater from Dobczyckie Lake containing MC-LR $\left(35 \mu \mathrm{g} \mathrm{L}^{-1}\right) 41.2 \pm 2.2 \%$ of toxin was degraded. Such degradation ability was stable over at least 2 days. The calculated efficiency of MC degradation was $100.3 \mu \mathrm{g} \mathrm{h}^{-1}$ per 1 litre of deposited beads (Fig. 5).

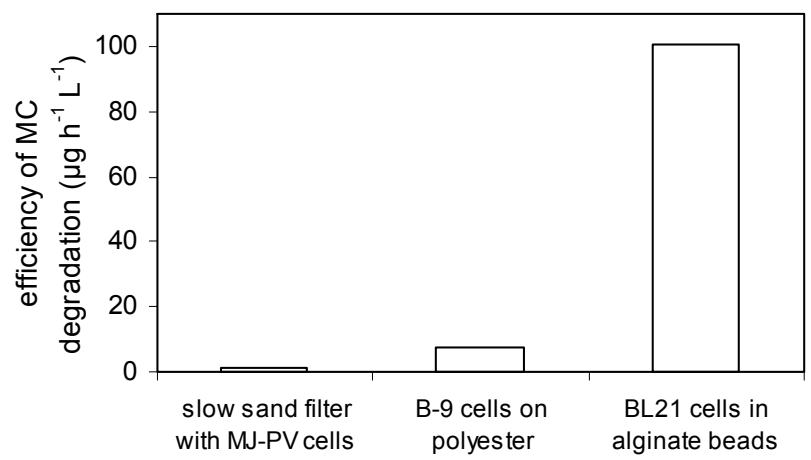

Fig. 5. Compared efficiency of three types of MC removal systems: 1) column with sand filter colonized by Sphingomonas MJ-PV cells [20], 2) bioreactor with Sphingomonas B-9 cells immobilized on polyester [21] and 3) column with alginate entrapped BL21_MlrA cells [present paper]. The values were calculated for $1 \mathrm{~L}$ of bioreactor or column volume

\section{DISCUSSION}

So far, the proposed biotechnological systems for the removal of cyanotoxins have assumed the use of naturally occurring bacterial strains. Several experiments indicated that biologically active filters (granular activated carbon and sand) may be an attractive water treatment option [17]-[19]. It has been documented that MC removal in this system is not only due to physical processes but mainly to biological degradation. Such filtration systems are based on undefined microorganisms collected from raw freshwater. A different pilot-scale study was performed by Bourne et al. [20] and Tsuji et al. [21] who proposed systems with immobilized bacteria belonging to Sphingomonas with known biodegradation activity. In the work of Bourne et al. [20] an individual slow sand filter column was constructed of a sand bed with defined size and a PVC cartridge to avoid algal growth. Filters were inoculated with a Sphingomonas strain (population of $5 \times 10^{8}$ cells, in a volume of $10 \mathrm{~mL}$ ). The documented MC degradation was $80 \%$ within 2 days. In the system proposed by Tsuji et al. [21], the bacterial strain Sphingomonas sp. B-9 was immobilized on polyester in a continuous bioreactor (cell density $7.9 \times 10^{6}$ cells $\mathrm{mL}^{-1}$ ). The removal capability of over $80 \%$ MC continued for almost 2 months. After comparing the volume of the bioreactors and 
unification of this size to $1 \mathrm{~L}$, the efficiency of these systems was $1.32 \mu \mathrm{g} \mathrm{h}^{-1} \mathrm{~L}^{-1}$ [20] and $7.50 \mu \mathrm{g} \mathrm{h}^{-1} \mathrm{~L}^{-1}$ [21]. This calculation indicates, due to the low MC degradation rate, that the systems offer low efficiency and their use in fast filtration of large amount of water contaminated with MCs is questionable.

A possible solution of these problems may be a significant increase of in the MC degradation potency of the used systems through utilisation of genetically engineered microorganisms. In this manuscript the modified E. coli BL21 strain with high MC-degradation potency was proposed as an alternative source of MC-degrading microorganism which may be employed in the bioremediation process.

Despite significant reduction of MlrA activity within 4 weeks BL21_MlrA cells still indicated high potency to decompose MCs. Similarly, the immobilized cells may also express relatively high MlrA activity for a few weeks (Fig. 3 $A$ and B). Such potency makes the modified strain a promising alternative in comparison with wild strains.

In the present paper a new option of MC-degrading bacteria immobilization has been proposed. Gel entrapment in natural polysaccharide matrixes is the most widely used immobilization technique for microorganisms [22]. Among them, alginate is commonly employed. A huge advantage of alginate gel entrapment is that immobilization is relatively gentle and cells are not exposed to extreme physical-chemical conditions. Additionally, no toxicity, good permeability and transparency of formed beads provide beneficial structure for cells in the context of their expected activity [22]. Our preliminary experiments indicated that BL21_MlrA cells can be immobilized in alginate successfully. The obtained alginate beads packed in a narrow column (Fig. 3) allowed to eliminate MC-LR from the solution very quickly which is extremely important in the context of possible practical application. In comparison with the bioreactor based on immobilization of wild strains [20], [21] the efficiency of MC degradation was 75 and 13 times higher, respectively (Fig. 5]. The initial cellular concentration needs to be optimized because it is a very important parameter; higher initial cellular density should result in the higher final MC-degradation ability. Similarly, some other parameters have to be optimized e.g. the proportion of cells and alginate or the length of the column. It is expected that in a longer column the complete $\mathrm{MC}$ removal will take place. Nevertheless, promising MC degradation capacity of environmentally relevant toxin concentrations indicates a high potential of such inexpensive infrastructure and the advantages of using modified bacteria for bioremediation applications.

\section{CONCLUSION}

In this study some original ideas were tested: 1) the usefulness of genetically modified bacteria in microcystin degradation; 2) the activity of alginate entrapped bacteria toward MCs; 3) the efficiency of a column packed with such immobilized cells during constant flow of MC contaminated freshwater. The results indicate that modified bacteria with high MlrA activity may be also active toward MC when immobilized in alginate beads. In the next step possible application of such a constructed system should be tested in details.

\section{ACKNOWLEDGMENT}

Grateful acknowledgments to Jussi Meriluoto for his help in grant application and for all his suggestions and ideas.

\section{REFERENCES}

[1] S. Metcalf and G. A. Codd, "Microwave oven and boiling waterbath extraction of hepatotoxins from cyanobacterial cells," FEMS Microbiology Letters, vol. 184, pp. 241-246, 2000

[2] K. I. Harada, "Chemistry and detection of microcystins," in Toxic microcystis, M.F. Watanabe, K.-I. Harada, W.W. Carmichael, H. Fujiki, Eds. Boca Raton, USA: CRC Press, 1996, pp. 103-148.

[3] B. W. Ibelings and I. Chorus, "Accumulation of cyanobacterial toxins in freshwater "seafood" and its consequences for public health: a review," Environmental Pollutants, vol. 150, pp. 177-92, 2007

[4] E. Funari and E. Testai, "Human health risk assessment related to cyanotoxins exposure," Critical Reviews in Toxicology, vol. 38, pp. 97-125, 2008

[5] M. T. L. Craig, H. A. Luu, T. L. McCready, D. Williams, R. J. Andersen, and C. F. B. Holmes, "Molecular mechanism underlying the interaction of motuporin and microcystins with type-1 and type-2A protein phosphatase," Biochemistry and Cell Biology, vol. 74, pp. 569-578, 1996

[6] T. Yoshida, et al., "Immunohistochemical localization of microcystin-LR in the liver of mice: A study on the pathogenesis of microcystin-LR-induced hepatotoxicity," Toxicologic Pathology, vol. 26, pp. 411-418, 1998

[7] W. W. Carmichael, "The toxins of cyanobacteria," Scientific American, vol. 270 , pp. 64,1994

[8] D. Singh, M. B. Tyagi, and A. Kumar, "Cyanobacterial toxins," in Cyanobacterial and algal metabolism and environmental biotechnology. Fatma, T. Ed. New Delhi, India: Narosa Publishing House, 1999, pp. 61-72.

[9] I. Chorus and J. Bertram, WHO Toxic cyanobacteria in water - a guide to their public health - consequences, monitoring and management. New York, USA: E \& FN SPON, 1999, pp. 416.

[10] M. Welker and C. Steinberg, "Rates of humic substance photosensitized degradation of microcystin-LR in natural waters," Environmetal Sciences and Technology, vol. 34, pp. 3415-3419, 2000

[11] K. Tsuji, H. Masui, H. Uemura, Y. Mori, and K.I. Harada, "Analysis of microcystins in sediments using MMPB method," Toxicon, vol. 39, pp. 687-692, 2001

[12] C. Edwards and L. A. Lawton, "Bioremediation of Cyanotoxins," Advanced in Applied Microbiology, vol. 67, pp. 109-129, 2009

[13] D. G. Bourne, G. J. Jones, R. L. Blakeley, G. J. Jones, A. P. Negri, and P. Riddles, "Enzymatic pathway for the bacterial degradation of the cyanobacterial cyclic peptide toxin microcystin LR," Applied and Environmental Microbiology, vol. 62, pp. 4086-4094, 1996

[14] D. Dziga, B. Wladyka, G. Zielińska, J. Meriluoto, and M. Wasylewski, "Heterologous expression and characterisation of microcystinase," Toxicon, vol. 59, pp. 578-586, 2012

[15] K. Shimizu, H. Maseda, K. Okano, T. Kurashima, Y. Kawauchi, Q. Xue, M. Utsumi, Z. Zhang, and N. Sugiura, "Enzymatic pathway for biodegrading microcystin LR in Sphingopyxis sp. C-1," Journal of Bioscience and Bioengineering, vol. 114, pp. 630-634, 2012

[16] D. Dziga, M. Wasylewski, A. Szetela, O. Bocheńska, and B. Wladyka. "Verification of the Role of MlrC in Microcystin Biodegradation by Studies Using a Heterologously Expressed Enzyme," Chemical Research in Toxicology, vol. 25, pp. 1192-1194, 2012

[17] L. Ho, T. Meyn, A. Keegan, D. Hoefel, J. Brookes, C. P. Saint, and G. Newcombe, "Bacterial degradation of microcystin toxins within a biologically active sand filter," Water Research, vol. 40, pp. 768-774, 2006

[18] G. Grutzmacher, G. Bottcher, I. Chorus, and H. Bartel, "Removal of microcystins by slow sand filtration," Environmental Toxicology, vol. 17, pp. 386-394 2002

[19] G. Newcombe, D. Cook, S. Brooke, and N. Slyman, "Treatment options for microcystin toxins: Similarities and differences between variants" Environmental Toxicology, vol. 24, pp. 299-308, 2003 
[20] D. G. Bourne, R. L. Blakeley, P. Riddles, and G. J. Jones, "Biodegradation of the cyanobacterial toxin microcystin LR in natural water and biologically active slow sand filters," Water Research, vol. 40, pp. 1294-1302, 2006

[21] K. Tsuji, M. Asakawa, Y. Anzai, T. Sumino, and K. Harada, "Degradation of microcystins using immobilized microorganism isolated in an eutrophic lake," Chemosphere, vol. 65, pp. 117-124, 2006

[22] I. M. Garrido, "Microalgae immobilization: Current techniques and uses," Bioresource Technology, vol. 99, pp. 3949-3964, 2008
Dariusz Dziga was born in Tarnow, Poland. Date of birth January 11, 1973. He got his Ph.D. degree in 2001 in biology in the field of biochemistry (Institute of Molecular Biology, Jagiellonian University. Since 2001 he has worked in Faculty of Biochemistry, Biophysic and Biotechnology, Jagiellonian University, Krakow, Poland. His current position is assistant lecturer. Area of his specialization is cyanobacterial toxins. His recent publications have been focused on the biodegradation of hepatotoxic microcystins (published in Toxicon and Chemical Journal of Toxicology). Additional scientific interest is biohydrogen production. 